\title{
RADIOPHARMACEUTICAL DOSE DISTRIBUTION IN DIFFERENT ORGANS AND TISSUES FOR Lu-177 WITH DIFFERENT CARRIER
}

\author{
Hesham MH Zakaly ${ }^{1.3}$, Mostafa. Y. A. Mostafa ${ }^{1,4}$, M Zhukovsky $^{2}$ \\ 1) Ural Federal University, Yekaterinburg, Russia \\ 2) Institute of Industrial ecology UB RAS, Ekaterinburg, Russia \\ 3) Al-Azhar University, Assuit Branch, Physics Department, Assuit, Egypt \\ 4) Minia University, faculty of Science, Department of Physics, El-Minia, Egypt \\ *E-mail: h.m.zakaly@gmail.com
}

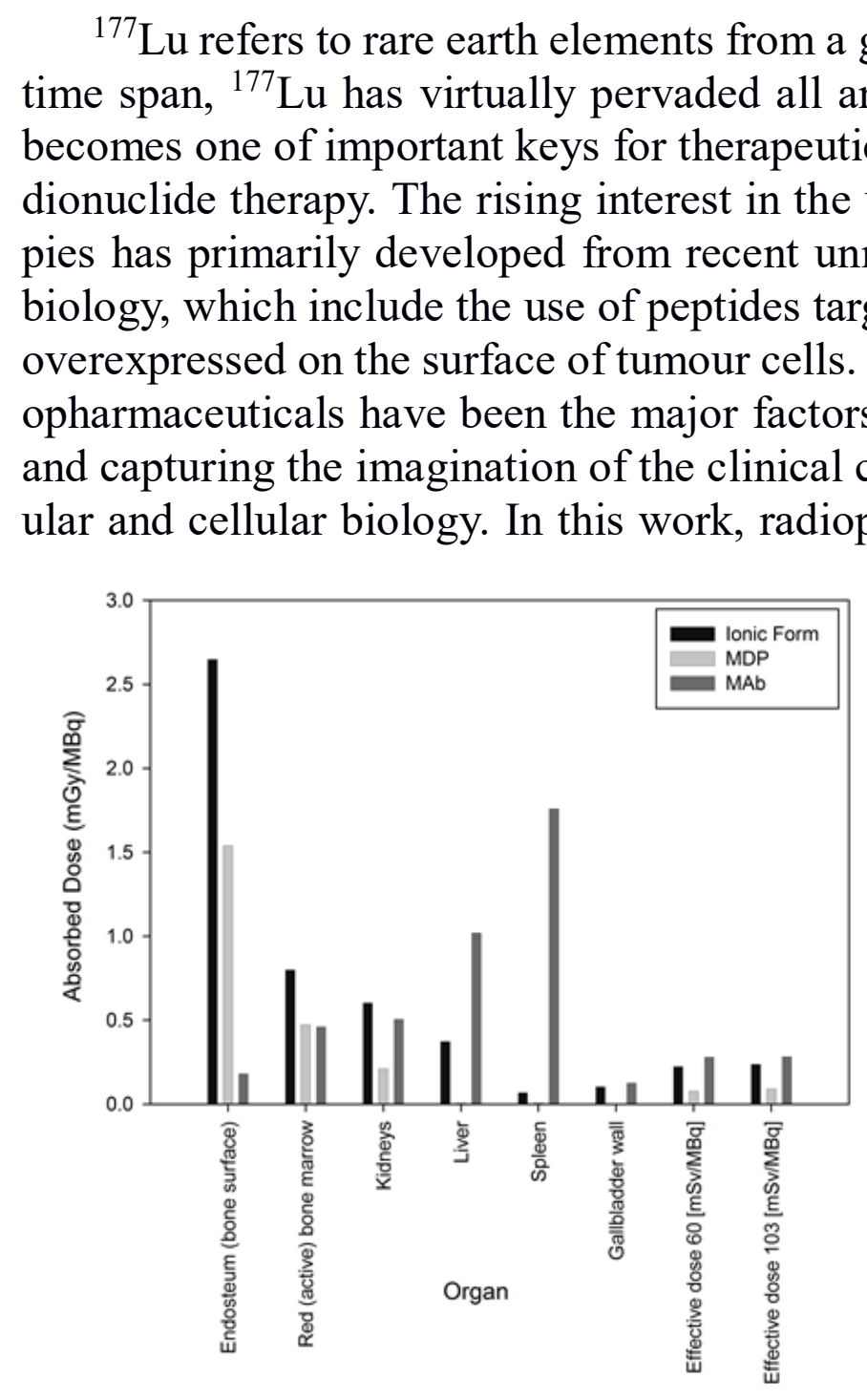

Fig. 1. Main organs absorbed dose sorbed dose in health human organs and tissues is presented. The comparison between unlabelled ${ }^{177} \mathrm{Lu}$ (ionic form) and labelled with ${ }^{177} \mathrm{Lu}-\mathrm{MDP}$ (methylenediphosphonate) and ${ }^{177} \mathrm{Lu}-$ MAb (monoclonal antibodies). The biokinetic model in each case are described and presented. The absorbed dose in health human organs and tissues are simulated with two recommended programs WinAct and IDAC 2.1 (Internal Dose Assessment by Computer) software ${ }^{1}$. The distribution of absorbed dose in the main organs nearly the same with different in the value for the ionic form and ${ }^{177} \mathrm{Lu}-$ MDP. The absorption in the case of ionic form is high (Fig.1). the distribution is completely change while ${ }^{177} \mathrm{Lu}-\mathrm{Mab}$ is used. The most absorbed dose fraction goes to spleen and liver unlike bone surface absorb nearly $50 \%$ of dose.

1. Mostafa. Y.A.M et al., Radiological Physics and Technology, in press (2019). 